\title{
ArcheoSciences
}

Revue d'archéométrie

33 (suppl.) | 2009

Mémoire du sol, espace des hommes

\section{Archaeological prospection in the Swedish mountain tundra region}

Andreas Viberg, Immo Trinks and Kerstin Lidén

\section{(2) OpenEdition}

1 Journals

Electronic version

URL: https://journals.openedition.org/archeosciences/1524

DOI: 10.4000/archeosciences. 1524

ISBN: 978-2-7535-1599-4

ISSN: 2104-3728

Publisher

Presses universitaires de Rennes

Printed version

Date of publication: 30 October 2009

Number of pages: 167-169

ISBN: 978-2-7535-0943-6

ISSN: $1960-1360$

\section{Electronic reference}

Andreas Viberg, Immo Trinks and Kerstin Lidén, "Archaeological prospection in the Swedish mountain tundra region", ArcheoSciences [Online], 33 (suppl.) | 2009, Online since 30 October 2011, connection on 01 February 2022. URL: http://journals.openedition.org/archeosciences/1524 ; DOI: https://doi.org/ 10.4000/archeosciences. 1524 


\title{
Archaeological prospection in the Swedish mountain tundra region
}

\author{
Andreas ViberG* ${ }^{*}$ Immo Trinks ${ }^{* *}$ and Kerstin LidÉN*
}

Key words: Magnetic susceptibility, Phosphate, Sweden, Archaeological Prospection, Stone Age.

\section{INTRODUCTION}

During the International Polar Year (IPY) 2007-2008 scientists from over 60 nations have examined the Arctic and Antarctic environments from different scientific perspectives in over 200 different projects ${ }^{1}$. The focus of the IPY in Sweden has been set on studies of climate change as well as of human cultures and societies in the polar region. These studies were considered important not only from an environmental but also from a cultural perspective. The project Arctic Sweden focused on the mountain tundra region in northern Sweden.

Due to the fact that most archaeological excavating investigations in Sweden are connected to infrastructure development projects in southern and central parts of the country, the northern mountain regions have seen fairly little archaeological investigations and digs. The IPY offered an opportunity to expand our knowledge about the people living in Arctic Sweden in prehistoric times.

During three weeks in the summer of 2008 archaeologists from Stockholm and Umeå Universities teamed up with archaeologists from Västerbottens County museum to excavate a Stone Age site (RA ̈̈ 1372) at the shores of lake Luspasjaure in the province of Lapland, Sweden. The lake is situated 917 metres above sea level making RAÄ 1372 the highest elevated settlement site in Sweden. The site was discovered in 2001 when archaeologists from Västerbottens County museum made an inventory of archaeological remains in the area. They found an area of approximately $5000 \mathrm{~m}^{2}$ covered with scattered debris from Stone Age tool production. The archaeological objective of the 2008 campaign was to locate possible traces of a settlement by excavations and geophysical archaeological prospection surveys. Due to the remote location of the site the transportation of personnel and equipment was done by helicopter. Electricity in the excavation camp for recharging of geophysical equipment, total station and computers was generated by a portable wind-power station and solar panels.

\section{GEOLOGICAL PRECONDITIONS AND SUITABLE PROSPECTION METHODS}

The site is situated above the treeline and the quaternary soil consists mostly of till and weathered deposits, differing in thickness from a decimetre down to a centimetre. The shallow bedrock in the area is dominated by black shale with inclusions of quartzite. The terrain is hilly and the thin soil layer is covered with many small stones. Consequences of the high altitude are powerful spring floods and large amounts of snow during winters. The geology and natural conditions in this region pose special demands on geophysical archaeological prospection surveys.

The choice of method for archaeological prospection at the site was limited by the above described conditions. Due

* Archaeological Research Laboratory, Stockholm University, Sweden. (andreas.viberg@arklab.su.se)

** UV-Teknik, Archaeological Excavation Department, Swedish National Heritage Board, Sweden.

1. [http://www.ipy.org] 
to the uneven terrain, the thin soil layer and a surface covered with stones (Fig. 2) and low growing bushes, a ground penetrating radar (GPR) survey was deemed impossible. A magnetometry survey may be suitable if the magnetic effect of the shallow bedrock does not overshadow magnetic anomalies of interest. A magnetic susceptibility survey of the thin soil layer was considered as a suitable approach for locating areas of prehistoric activity at the site (Le Borgne, 1955; Tite and Mullins, 1971; Scollar, 1990; Dalan, 2008). A Bartington MS2 magnetic susceptibility meter (MS2D) was generously provided for the survey by the manufacturer. In addition a Geonics EM-38 was used for the survey to study the effect of the shallow bedrock on the results. A comparison between the EM-38 and the MS2D system might reveal the potential of a possible future magnetometry survey (Fig. 1).

Another archaeological prospection approach which may be particularly suitable at this site is geochemical phosphate mapping. This method has enjoyed great popularity in Swedish archaeology since the 1930s (Arrhenius, 1935). Using the phosphate method as a prospecting tool is however not unproblematic for several reasons (Bethell and Máté, 1989; Crowther, 1997). A common problem is that of comparability of samples. Normally, when taking soil samples with a probe there is no warranty that the collected samples originates from the same layer. In the case of the Swedish mountain tundra region however, there most often only exists one soil layer. This suggests that this region may justify the use of the method. Another general problem of the method is the differentiation between recent and pre-historical phosphate depositions. In order to test the method a field phosphate analysis kit from Merck was used (Persson, 1997).

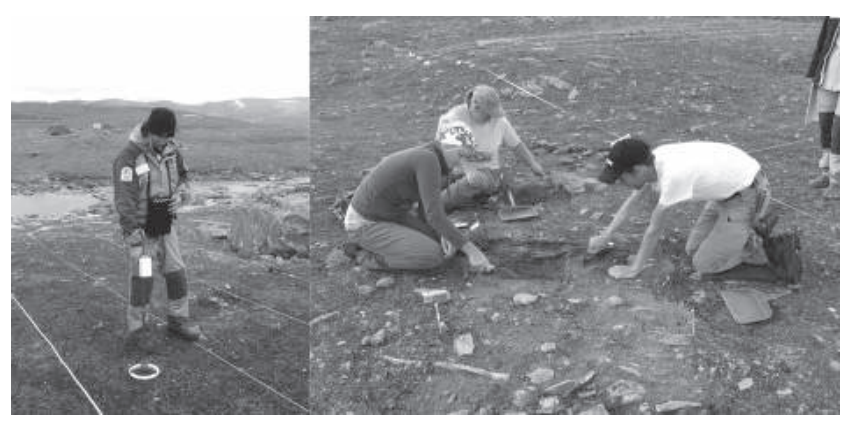

Figure 2. (left) Magnetic susceptibility survey with $0.5 \mathrm{~m}$ sample spacing. Photo: Kerstin Lidén. (right) Archaeological excavation of the thin cultural layer. Note the abundance of stones in the soil. Photo: Andreas Viberg.

A total area of $1296 \mathrm{~m}^{2}$ was surveyed during a period of approximately 2 weeks. Measurements were taken with 0.5 meter sample spacing (Fig. 2) (in-line as well as crossline) in case of both the Bartington MS2D and Geonics EM-38 surveys.

Soil samples for phosphate analysis were for practical reasons collected with 5 meter spacing (in-line as well as crossline). The results of the measurements have been converted into maps using Surfer 8.

\section{RESUlTS OF THE ARCHAEOLOGICAL PROSPECTION AND THE SUBSEQUENT EXCAVATION}

The field phosphate analysis kit did not prove to be useful since its reagent $\left(0.2 \mathrm{M} \mathrm{H}_{2} \mathrm{SO}_{4}\right)$ did not react below temperatures of $15^{\circ} \mathrm{C}$. This prevented a quick analysis in the field
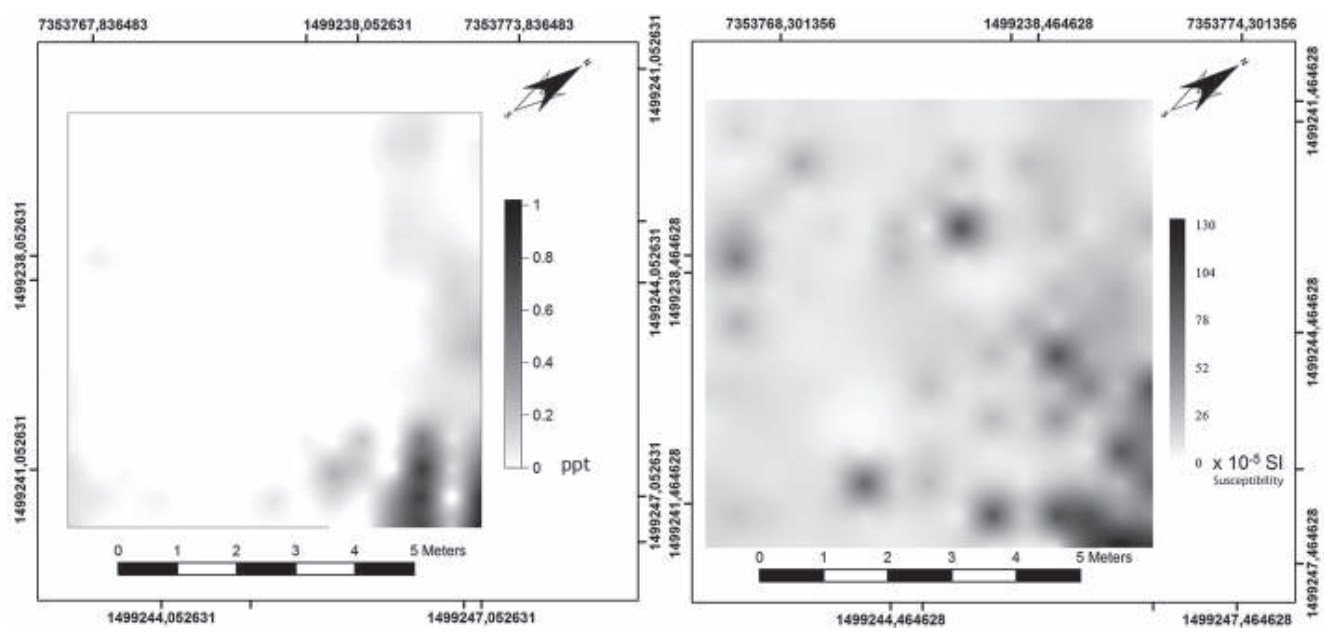

Figure 1: A comparison between EM-38 and MS2D results. (left) EM-38 Inphase mode. (right) MS2D results. The MS2D values should be multiplied by $1,5 \times 10^{-5}$ to account for the rough terrain if comparisons with other areas are to be done. 
Figure 3. (left) MS2D results from the two survey areas and their spatial relationship. The lower left corner of the two areas is marked with a grey dot. (right) Results from the MS2D measurements directly over the waste heap with fire cracked stones at RAÄ 1372. The values should be multiplied by $1,5 \times 10^{-5}$ to correct for the rough terrain if comparisons with other areas are to be done.
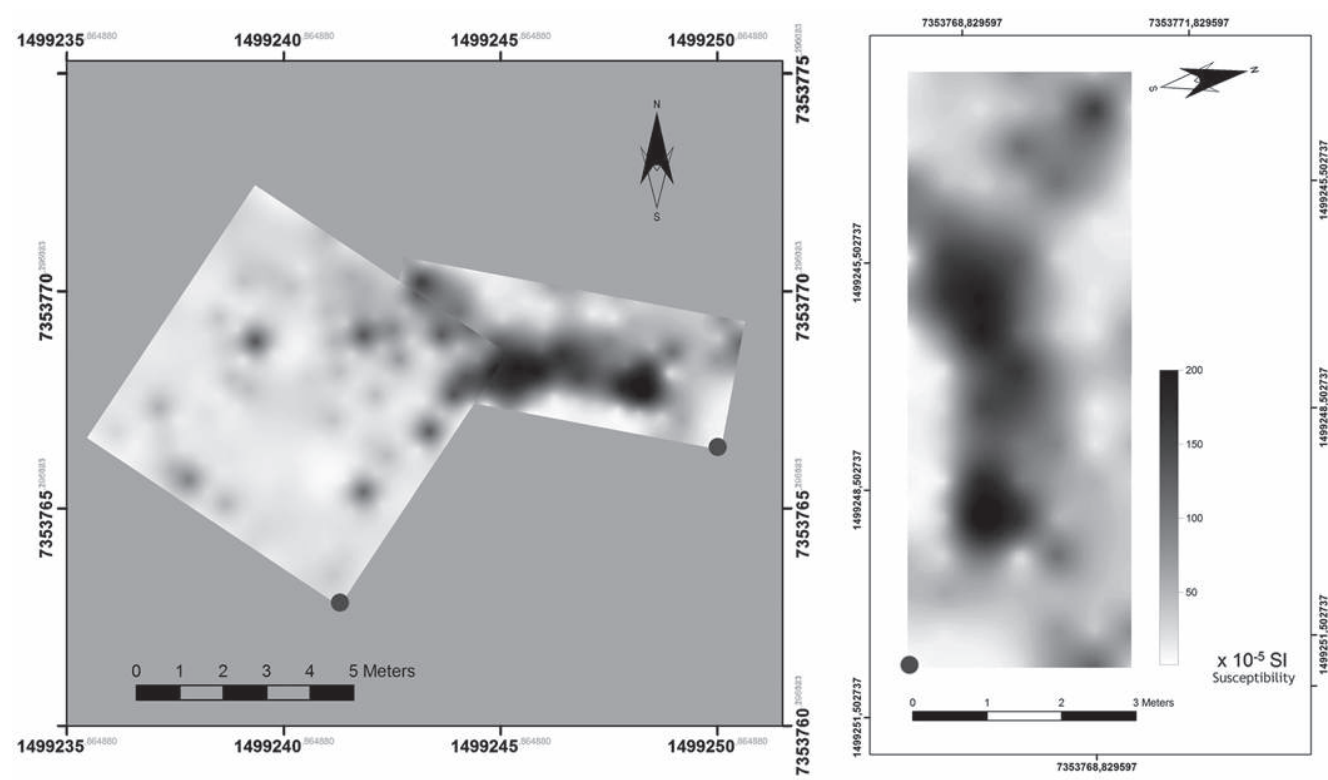

and instead soil samples were taken back to the laboratory for analysis.

The anomalies contained in the geophysical data were explained by the subsequent archaeological excavation. A waste heap consisting mainly of organic material and fire cracked stones situated well within the estimated settlement area was detected and was visible in both the MS2D and EM-38 data (Fig. 1). This suggests that a magnetometer survey could be successful when looking for similar remains. A second survey area was established to define the boundaries of the waste heap (Fig. 3). The fire cracked stones found within the waste heap were interpreted to have been used during the preparation of food. The heap was the most important feature identified during the excavations. Important finds from the excavations include different kinds of quartzite and shale tools as well as different pieces of resin which probably was used in the tool making process. One piece of resin has been sent for ${ }^{14} \mathrm{C}$ dating.

\section{Acknowledgements}

We would like to acknowledge Tessa Evans of Bartington Instruments for kindly providing the MS2D susceptibility meter for the survey and IPY for logistic support.

\section{References}

Arrhenius, O., 1935. Markundersökning och arkeologi. Fornvännen, 30: 65-76.

Bethell, P., Máté, I., 1989. The use of phosphate analysis in archaeology: a critique. In Henderson, J., (dir.). Scientific Analysis in Archaeology. University committee for Archaeology, Oxford.

Crowther, J., 1997. Soil Phosphate Surveys: Critical Approaches to Sampling, Analysis and Interpretation, Archaeological prospection, 4: 93-102.

Dalan, R.A., 2008. A Review if the Role of Magnetic Susceptibility in Archaeogeophysical Studies in the USA: Recent Developments and Prospects. Archaeological prospection, 15: 1-31.

Le Borgne, E., 1955. Susceptibilité magnétique anormale du sol superficial. Annales de Géophysique, 11: 399-419.

Scollar, I., Tabbagh, A., Hesse, A., Herzog, I., 1990. Archaeological Prospecting and Remote Sensing. Cambridge University Press, Cambridge.

Tite, M.S., Mullins, C., 1971. Enhancement of the Magnetic Susceptibility of Soils on Archaeological Sites. Archaeometry, 13, (2): 209-219.

Persson, K., 1997. Soil phosphate analysis: A new technique for measurement in the field using a test strip. Archaeometry, 39, (2): 441-443. 